\title{
Synthesis and characterization of polystyrene-block- poly(vinylbenzoic acid): a promising compound for manipulating photoresponsive properties at the nanoscale
}

\author{
Ana S. Abreu - M. Oliveira - P. V. Rodrigues • \\ I. Moura • G. Botelho • A. V. Machado
}

Received: 29 October 2014 / Accepted: 5 January 2015

(c) Springer Science+Business Media New York 2015

\begin{abstract}
Using reversible addition-fragmentation chain transfer (RAFT) polymerization, the effect of PSt macroRAFT and 4VBA ratio on the synthesis of a carboxylic acid functional block copolymer (PSt- $b$-P4VBA) was studied. PSt macroRAFT polymer was initially prepared followed by the insertion of 4-vinylbenzoic acid (4VBA) monomer. The chemical structure of the diblock copolymer was confirmed by NMR and FTIR. The effect of PSt macroRAFT and 4VBA ratio on copolymerization yield and on molecular weight distribution was assessed by gel permeation chromatography. The rate of polymerization did not change as the 4VBA/PSt macroRAFT ratio increased, indicating an ideal amount of 4VBA insertion. An optimal ratio of [PSt macroRAFT]:[AIBN]:[4VBA] was 1.2:1:180. DSC and XRD confirmed the amorphous structure of homo and copolymer. Thermal stability was higher for PSt- $b$-P4VBA forming activated porous carbon char by dehydration, carbonization and oxidation. SEM and STEM observations showed a morphological evolution between PSt macroRAFT and the correspondent copolymer.
\end{abstract}

\footnotetext{
A. S. Abreu ( $₫) \cdot$ M. Oliveira · P. V. Rodrigues · I. Moura ·

A. V. Machado

Institute of Polymers and Composites (IPC) and Institute of

Nanostructures, Nanomodelling and Nanofabrication (I3N),

University of Minho, Campus de Azurém, 4800-058 Guimarães,

Portugal

e-mail: anasofiaabreu@dep.uminho.pt

G. Botelho

Center/Department of Chemistry, University of Minho, Campus

de Gualtar, 4710-057 Braga, Portugal
}

\section{Introduction}

Controlled radical polymerization (CRP) techniques have been widely used for the preparation of several block copolymers that have controlled molecular weight, narrow polydispersity (PDI), and well-defined architecture (e.g., block, gradient and graft copolymers and stars). The CRP allows to obtain polymeric materials with properties once thought impossible to achieve by free radical processes [1]. The most useful CRP techniques include nitroxide-mediated polymerization (NMP) [2], atom transfer radical polymerization (ATRP) [3, 4], and reversible addition-fragmentation chain transfer (RAFT) polymerization [1,5]. Comparing to the NMP and ATRP, the RAFT polymerization presents the advantage of compatibility with a wide range of monomers including functional monomers, free of transition metal ion contamination, compatible with many reaction conditions, and various organic and aqueous solvents [6].

RAFT polymerization has made a huge impact on macromolecular design, namely in the synthesis of block copolymers, macromolecules that incorporate two or more sequences of monomers. In the overall RAFT polymerization, an initial RAFT agent, a thiocarbonylthio compound, is converted into a polymeric macro-RAFT agent by sequential insertion of monomer units into a $\mathrm{C}-\mathrm{S}$ bond. A successful outcome in RAFT polymerization depends on the selection of the RAFT agent for the specific monomers and reaction conditions [7]. The leaving and the activating groups of the thiocarbonylthio are retained at the ends of the resulting polymers [8]. This results in polymers with specific functional end groups, according to the RAFT agent selected, which can be submitted to a variety of post-polymerization modifications [9].

A block copolymer can self-assemble to form a nanoscale structure with a domain spacing that depends on molecular weight, segment size, and the strength of interaction between 
the blocks, represented by the Flory-Huggins interaction parameter, $\chi[10]$. Block polymers can assume a wide diversity of nanometer-scale morphologies, including lamellar, hexagonally packed cylindrical, and body-centered cubic structures, due to the incompatibility and the connectivity constraints between the chemically distinct segments. A typical periodicity is in the range $10-200 \mathrm{~nm}$. The morphology depends on $\chi$ parameter and the composition of the copolymer, parameterized as the volume fraction of one of the constituent blocks. Block copolymers may also be added as a minor component to control the morphology of a blend, acting as a compatibilizer [11]. Due to their unique architecture and self-assembly properties, block copolymers can be used in many potential applications such as nanolithography, polymer therapeutics, drug delivery, biosensors, plastic solar cells, microelectronics, desalination membranes, cosmetics, lubricants, surfactants, paints, inks, and adhesives [12].

Vinyl monomers, with certain chemical functions, are an interesting group suitable to be polymerized under CRP technics. It allows to prepare polymers with reactive functional side groups, which can be used for further post-polymerization reactions such as click chemistry or carbodiimide coupling reactions, among others [6]. Between vinyl monomers, styrenic families containing neutral, anionic, cationic, and zwitterionic hydrophilic functionality have been successfully employed on the RAFT synthesis of copolymers [13-16]. 4-Vinylbenzoic acid (4VBA), sensitive to temperature and $\mathrm{pH}$, is established as a smart building block $[14,17]$. This monomer is extremely valuable for the synthesis of highly functionalized polymeric architectures. The main advantage is the possibility of coupling it with amino or hydroxyl groups present in other molecules. Structural close to styrene is expected that $4 \mathrm{VBA}$ combines the excellent properties of polystyrene with the functionalization flexibility of the esterification reactions [17]. Lowe et al. prepared a copolymer of $\mathrm{N}$-isopropylacrylamide and 4VBA capable to undergo supramolecular self-assembly in aqueous mediums [14]. The 4VBA monomer was also chemically modified by Aamer et al. to prepare a new activated ester monomer $N$ succinimide $p$-vinylbenzoate (NSVB) to be further polymerized under RAFT conditions [18].

Therefore, in this work, polystyrene-block-poly(4-vinylbenzoic acid) (PSt- $b$-P4VBA), a functionalized block copolymer by RAFT polymerization (Scheme 1), was synthesized and the effect of different [PSt macroRAFT]:[4VBA] molar ratio on the copolymer conversion and on the PSt- $b$-P4VBA molecular weight distribution was investigated. First, PSt macroRAFT polymer was synthesized [19], as the initial block, followed by polymerization of the functionalized 4-vinylbenzoic acid monomer. Different [PSt macroRAFT]:[AIBN]:[4VBA] ratios were tested. ${ }^{1} \mathrm{H}$ and ${ }^{13} \mathrm{C}$ NMR and FTIR were used to evaluate the chain-end structure of the resulting PSt- $b$-P4VBA. DSC, TGA, SEM, and STEM techniques were used for characterization and morphology visualization of the homo and new copolymer. Mean diameter and polydispersity index of the nanostructured polymer and block copolymer in solution were evaluated by DLS measurements.

\section{Experimental}

Copolymer synthesis

\section{Materials}

Benzyl benzodithioate (BDTB, Aldrich $96 \%$ ), 2,2'-azobis(2-methylpropionitrile) (AIBN, Aldrich $98 \%$ ), styrene (St, Acros Organics 99.5\%), 4-vinylbenzoic acid (4VBA, Acros Organics $96 \%$ ), $N, N$-dimethylformamide (DMF, Aldrich $99.9 \%$ ), tetrahydrofuran (THF, Aldrich $99.9 \%$ ), and methanol (MeOH, Acros Organics $99.9 \%$ ) were used as received.

\section{Synthesis of linear PSt macroRAFT agent}

[19] This initial synthetic procedure was performed using [St]:[AIBN]:[BDTB] in 480:1:1.4 ratio. Typically, a mixture of St $(25 \mathrm{~mL}, 22.72 \mathrm{~g}, 0.218 \mathrm{~mol})$, BDTB $(0.177 \mathrm{~g}$, $0.728 \mathrm{mmol}$ ), and AIBN (74.5 mg, $0.454 \mathrm{mmol}$ ) was added into a 50-mL Schlenk tube equipped with a magnetic stirring bar and sealed with a rubber septum. After the mixture was degassed by three freeze-evacuate-thaw cycles, pure nitrogen gas was introduced into the tube, which was subsequently immersed in a thermostatic oil bath at $110^{\circ} \mathrm{C}$ for $5 \mathrm{~h}$. Polymerization was stopped by placing the tube in an ice

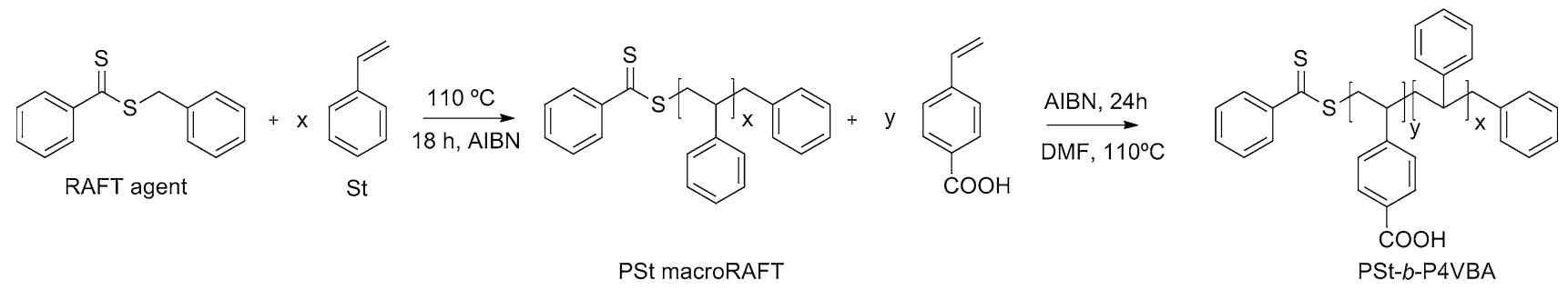

Scheme 1 Synthetic route followed to prepare PSt- $b$-P4VBA copolymer via RAFT polymerization 
bath. The reaction mixture was dissolved in THF. Resulting solution was then slowly poured into an excess of methanol under stirring in order to precipitate the polymer. Subsequently, the precipitate was collected by filtration and dried in a vacuum oven at room temperature for $36 \mathrm{~h}$. PSt macroRAFT was obtained at $79 \%$ yield as pink solid. $\delta_{\mathrm{H}}$ (400 MHz, $\mathrm{CDCl}_{3}$ ): 1.20-1.70 (broad m, aliphatic protons), 1.70-2.10 (broad m, aliphatic protons), 6.25-6.28 (broad m, phenyl protons), 6.30-7.25 (broad m, phenyl protons) ppm. The NMR spectrum did not show the presence of monomer. $M_{\mathrm{w}}(\mathrm{GPC}) 16403 \mathrm{~g} / \mathrm{mol}, M_{\mathrm{n}}(\mathrm{GPC}) 11852 \mathrm{~g} / \mathrm{mol}$ and with a polydispersity index (PDI) of 1.38 .

\section{Synthesis of linear copolymer PSt-b-P4VBA}

Typically, into a 25-mL Schlenk tube, PSt macroRAFT and 4-vinylbenzoic acid were added in different molar ratios, Table 1, in the presence of AIBN (1.7 mg, $0.014 \mathrm{mmol})$ and DMF $(1 \mathrm{~mL})$. After the mixture was degassed by three freeze-evacuate-thaw cycles, and placed under an inert nitrogen atmosphere, the tube was immersed in a thermostatic oil bath at $110{ }^{\circ} \mathrm{C}$. After $24 \mathrm{~h}$ of polymerization time, the tube was cooled down at room temperature immediately. The reaction mixture was evaporated under reduce pressure and placed in a vacuum oven at $110^{\circ} \mathrm{C}$ overnight. Washes in methanol afforded the block copolymer (PSt- $b$-P4VBA) as a white solid, after filtration and dried in a vacuum oven at room temperature for $24 \mathrm{~h} .{ }^{1} \mathrm{H} \mathrm{NMR}$ (400 MHz, DMSO- $d_{6}$ ): $\delta(\mathrm{ppm})=1.00-2.09\left(\right.$ broad $\mathrm{s}, \mathrm{CH}$ and $\left.\mathrm{CH}_{2}\right), 3.91-4.31$ (broad s, $\mathrm{CH}$ and $\mathrm{CH}_{2}$ ), 6.22-7.15 (broad m, ArH), 7.22-7.95 (broad m, ArH), 12.79 (broad s, OH). ${ }^{13} \mathrm{C}$ NMR (400 MHz, DMSO- $\left.d_{6}\right): \delta(\mathrm{ppm})=22.04(\mathrm{CH}), 26.60(\mathrm{CH}), 30.77(\mathrm{CH})$, $34.33(\mathrm{CH}), 35.78(\mathrm{CH}), 44.37(\mathrm{CH}), 48.61(\mathrm{CH}), 116.94$ $\left(\mathrm{CH}_{2}\right), 126.21(\mathrm{CH}), 127.37(\mathrm{CH}), 128.74(\mathrm{C}), 129.21(\mathrm{CH})$, $129.67(\mathrm{CH}), 130.06(\mathrm{CH}), 135.86(\mathrm{CH}), 141.26(\mathrm{C}), 149.46$ (C), $162.31(\mathrm{C}), 167.09(\mathrm{C}), 167.19(\mathrm{C}=\mathrm{O})$.

\section{Characterization}

Proton and carbon nuclear magnetic resonance $\left({ }^{1} \mathrm{H}\right.$ and ${ }^{13} \mathrm{C}$ NMR $)$ spectroscopy

The PSt- $b$-P4VBA block copolymer and PSt precursor were characterized by ${ }^{1} \mathrm{H}$ NMR spectroscopy in terms of their composition and purity using a $400 \mathrm{MHz}$ Avance Bruker NMR spectrometer equipped with an ultrashield magnet and using deuterated solvents. The PSt- $b$-P4VBA block copolymer was also characterized by ${ }^{13} \mathrm{C}$ NMR spectroscopy. The ${ }^{1} \mathrm{H}$ and ${ }^{13} \mathrm{C}$ NMR chemical shifts are reported in ppm (parts per million). Tetramethylsilane (TMS) or the residual solvent peaks have been used as an internal reference. Deuterated chloroform $\left(\mathrm{CDCl}_{3}\right)$ and dimethyl sulfoxide (DMSO- $d_{6}$ ) were used as solvents for NMR spectroscopy. Distortionless enhancement by polarization transfer (DEPT) technique was performed as ${ }^{13} \mathrm{C}$ DEPT-135 experiment to identify $\mathrm{CH}_{2}$ from $\mathrm{CH}$ protons.

\section{Gel permeation chromatography (GPC)}

GPC was used to assess the molecular weight of the prepared PSt macro RAFT and PSt- $b$-P4VBA copolymer. Solutions were prepared in THF $(99.9 \%)$ and prefiltered on filter plate (hydrophobic polytetrafluoroethylene, $0.45 \mu \mathrm{m}$ pore size) before injection. A Waters Alliance GPC Model 2695, equipped with 3 PLgel MIXED-B columns (inner diameter $=7.5 \mathrm{~mm}$, length $=30 \mathrm{~mm}$ and particle size $=$ $10 \mathrm{~mm}$ ) and a Waters 2410 Differential Refractometer as detector, was used for the determination. THF was used as an eluent with a flow rate of $1 \mathrm{~mL} / \mathrm{min}$ and the temperatures were 25 and $35{ }^{\circ} \mathrm{C}$ at the injector and detector, respectively. The molecular weights and PDIs were derived from a calibration curve based on narrow polystyrene standards.

\section{Fourier transformed infrared spectroscopy (FTIR)}

FTIR spectra of the PSt macroRAFT and PSt- $b$-P4VBA copolymer were recorded with a spectrometer (PerkinElmer 1720). Measurements were performed in a transmittance mode using a spectral range varying from 4000 to $400 \mathrm{~cm}^{-1}$. An amount of $20 \mathrm{mg}$ of each material was mixed with $200 \mathrm{mg}$ of $\mathrm{KBr}$ to prepare translucent sample disks used for FTIR analysis.

\section{$X$-ray diffraction measurements $(X R D)$}

XRD was performed to investigate the crystallinity of the PS macroRAFT and the PSt- $b$-P4VBA copolymer. XRD spectra of the samples were obtained at room temperature

Table 1 Experimental conditions for the RAFT polymerization of 4VBA into PSt macroRAFT

\begin{tabular}{llr}
\hline [PSt macroRAFT]:[AIBN]:[4VBA] & PSt macroRAFT & 4VBA \\
\hline $0.5: 1: 120$ & $(0.154 \mathrm{~g}, 0.009 \mathrm{mmol})$ & $(0.370 \mathrm{~g}, 2.5 \mathrm{mmol})$ \\
$1.2: 1: 180$ & $(0.272 \mathrm{~g}, 0.017 \mathrm{mmol})$ & $(0.370 \mathrm{~g}, 2.5 \mathrm{mmol})$ \\
$1.2: 1: 360$ & $(0.136 \mathrm{~g}, 0.008 \mathrm{mmol})$ & $(0.370 \mathrm{~g}, 2.5 \mathrm{mmol})$ \\
\hline
\end{tabular}


using a diffractometer (AXS Nanostar- D8 Discover, Bruker) equipped with a CuK $\alpha$ generator $(\lambda=1.5406 \AA)$ at $40 \mathrm{~mA}$ and $40 \mathrm{kV}$. Data were collected in a range of $0.08^{\circ}-10^{\circ}$ with a step size of $0.01^{\circ}$ and a counting time of $2 \mathrm{~s}$ per step. The polymer and copolymer powders were analyzed directly.

\section{Differential scanning calorimetry (DSC)}

Thermal properties of the prepared PSt macro RAFT and PSt- $b$-P4VBA were measured using a Perkin Elmer Diamond DSC 131 apparatus, equipped with an liquid nitrogen cooling system (LNCS) accessory. Samples (about $10 \mathrm{mg}$ ) are placed in $\mathrm{Al}$ pans and heated at $10{ }^{\circ} \mathrm{C} / \mathrm{min}$ from 10 to $170{ }^{\circ} \mathrm{C}$ under nitrogen flow. Glass transition temperatures $\left(\mathrm{T}_{\mathrm{g}}\right.$ 's) were taken as the midpoint of the change in heat capacity.

\section{Thermogravimetric analysis (TGA)}

Thermogravimetric measurements for all prepared materials were carried out using a TA Q500 thermobalance. Samples were heated from 40 to $700{ }^{\circ} \mathrm{C}$ at $10{ }^{\circ} \mathrm{C} / \mathrm{min}$ under a nitrogen flow $(50 \mathrm{~mL} / \mathrm{min})$.

\section{Dynamic light scattering (DLS)}

Mean diameter and size distribution (polydispersity index) of PSt macroRAFT and PSt- $b$-P4VBA in DMF were measured by dynamic light scattering (DLS) NANO ZS Malvern Zetasizer equipment (Worcestershire, UK), at $25{ }^{\circ} \mathrm{C}$, using a He-Ne laser of $633 \mathrm{~nm}$ and a detector angle of $173^{\circ}$. Three independent measurements were performed for each sample. Malvern dispersion technology software (Worcestershire, UK) was used with multiple narrow mode (high-resolution) data processing, mean size (nanometer), and error values were considered.

\section{Microscopy (SEM and STEM)}

Scanning electron microscopy (SEM) was carried out to analyze the PSt macroRAFT and copolymer (PSt- $b$-P4VBA) morphologies. SEM analysis was performed in a Leica Cambridge S360 microscope. The samples were previously coated with a gold thin film. STEM observations of the nanostructured PSt macroRAFT and copolymer were performed with a NanoSEM Nova200 (FEI), using an acceleration voltage of $15 \mathrm{kV}$. Samples were prepared by copper grid immersion in $0.002 \% \mathrm{w} / \mathrm{w}$ sample solution followed by DMF evaporation. The copper grids were then analyzed in a Philips CM120 transmission electron microscope.

\section{Results and discussion}

PSt- $b$-P4VBA copolymer was synthesized via BDTBmediated RAFT polymerization as the RAFT chain transfer agent and AIBN as the initiator, according to Scheme 1. The first step reaction consisted in the synthesis of PSt macroRAFT. The latter was obtained by RAFT polymerization of St in the presence of the RAFT agent (BDTB) and AIBN, according to Zamfir et al. [19]. The copolymerization of $4 \mathrm{VBA}$, as second step of the reaction, was performed using different ratios of PSt macroRAFT and 4VBA. To evaluate the diblock copolymer chains formation, the molecular weight of PSt macroRAFT and PSt- $b$ P4VBA was determined by GPC (Table 2).

From GPC data, it was possible to calculate the values presented in Table 2, using the equations below:

$\mathrm{M}_{\text {ntheo }}=\left[\frac{W_{\mathrm{M}}}{\frac{W_{\text {macroRAFT }}}{M_{\mathrm{W} \text { macroRAFT }}}}\right] *$ conversion $+M_{\mathrm{W}}$ macroRAFT,

where $W_{\mathrm{M}}$ and $W_{\text {macroRAFT }}$ are the weight of the $4 \mathrm{VBA}$ monomer and macroRAFT agent, respectively.

$M_{\mathrm{W}}$ macroRAFT, the molecular weight of macroRAFT agent $\left(\mathrm{M}_{\mathrm{W}}\right.$ macroRAFT $=16403 \mathrm{~g} / \mathrm{mol}$ determined by GPC).

Yield $(\%)=\left(\frac{\mathrm{Mn}_{\text {exp }}}{\mathrm{M}_{\text {ntheo }}}\right) \times 100$

According to the characterization results, a linear homopolymer precursor was successfully formed, similar data was reported by Zamfir et al. [19]. Table 2 lists the conversion percentage, molecular weight of the starting homopolymer and block copolymer, reaction yield and PDI. RAFT synthesis claims the addition of higher excess of monomer to face the polymerization. Notwithstanding, Table 2 shows that PSt- $b$-P4VBA $M_{\text {Wexp }}$ and PDI are independent of PSt macroRAFT/4VBA molar ratio used, indicating that there is an ideal amount of $4 \mathrm{VBA}$ for the complete consumption of PSt macroRAFT. All reactions were performed during $24 \mathrm{~h}$ of polymerization. An initial experiment using [PSt macroRAFT]:[AIBN]:[4VBA] reaction with 1.2:1:180 proportion was performed during $48 \mathrm{~h}$, data not shown, and the $M_{\text {Wexp }}$ obtained by GPC demonstrated to be lower than the $M_{\text {Wexp }}$ obtained for $24 \mathrm{~h}$. Therefore, $24 \mathrm{~h}$ reaction time was selected. Furthermore, increasing PSt macroRAFT did not lead to a decrease in monomer conversion, contradicting the well-known effect usually observed in RAFT polymerization [20, 21]. The 4VBA polymerization degree was the same for the three ratios studied (around 200 unities). This indicates that increasing 4VBA monomer/PSt macroRAFT ratio, the length of P4VBA block does not change. This might be 
Table 2 RAFT polymerization of 4 VBA into PSt macroRAFT

\begin{tabular}{|c|c|c|c|c|c|c|}
\hline $\begin{array}{l}\text { [PSt macroRAFT]: } \\
{[\text { AIBN]:[4VBA] }}\end{array}$ & $\begin{array}{l}\text { Conversion } \\
(\%)^{\mathrm{a}}\end{array}$ & $M_{\text {ntheo }}$ & $M_{\text {nexp }}$ & $\begin{array}{l}M_{\mathrm{Wexp}}(\text { degree of } \\
\text { polymerization) }^{\mathrm{b}}\end{array}$ & Yield $(\%)^{\mathrm{c}}$ & PDI \\
\hline PSt macroRAFT & 47 & 14974 & 11852 & $16403(155)$ & 79 & 1.38 \\
\hline $0.5: 1: 120$ & 60 & 40167 & 24848 & $45938(200)$ & 62 & 1.88 \\
\hline $1.2: 1: 180$ & 44 & 26176 & 25618 & 46837 (206) & 98 & 1.80 \\
\hline $1.2: 1: 360$ & 20 & 25373 & 22800 & 43964 (186) & 90 & 1.93 \\
\hline
\end{tabular}

${ }^{a}$ Gravimetric yield

b The theoretical molecular weight $\left(M_{\text {ntheo }}\right)$ calculated according to Eq. (1)

${ }^{c}$ The percentage yield calculated according Eq. (2)

associated to dead chains of PSt macroRAFT. It can also be noticed that PDI increases from the initial value of 1.38 for PSt macroRAFT to $1.80-1.90$ for PSt- $b$-P4VBA (Table 2). Zamfir et al., described the same behavior during PSt- $b$ PVP block copolymers formation, which was explained as a result of deactivated polymer generated during the synthesis of the PSt macroRAFT [19]. The $M_{\text {nexp }}$ values determined by GPC do not match with the theoretical predicted ones, based on the reaction quantities. This discrepancy reveals that for both PSt macroRAFT and PSt- $b$ P4VBA, the monomers did not reach $100 \%$ conversion. Similar results were observed by Anderson and co-workers for PSt- $b$-PMMA [22]. The authors attributed this difference to GPC standard calibration, in which the structural difference between polystyrene standards and the block copolymer not allow an exact molecular weight quantification.

The RAFT polymerization reaction yield was excellent for [PSt macroRAFT]:[AIBN]:[4VBA] in 1.2:1:180 (98\%) and 1.2:1:360 (90\%), which demonstrate that the first condition is the most suitable condition to be applied. These conditions allow the formation of PSt- $b$-P4VBA copolymer with similar molecular weight, without using an excess of 4VBA monomer.

Figure 1 depicts the controlled nature of the PSt macroRAFT and PSt- $b$-P4VBA polymerizations. Both homopolymer and block copolymer have the unimodal and narrow curves suggesting that no side reactions occurred during the synthesis. Otherwise, PSt- $b$-P4VBA GPC curves shift to lower retention times and broadened relative to PSt macroRAFT, demonstrating the livingness of polymer chains and indicating polymer backbone growth and therefore higher molecular weight chains.

${ }^{1} \mathrm{H},{ }^{13} \mathrm{C}$ NMR spectra of PSt- $b$-P4VBA copolymer in DMSO- $d_{6}$ are depicted in Fig. 2. In ${ }^{1} \mathrm{H}$ NMR, a broad singlet (12.79 ppm) attributed to the hydroxyl proton of the carboxylic acid group present in P4VBA block can be observed. The aromatic protons region of the copolymer can be detected by peaks assigned at chemical shifts between $6.22-7.15$ and $7.22-7.95 \mathrm{ppm}$. It seems that the

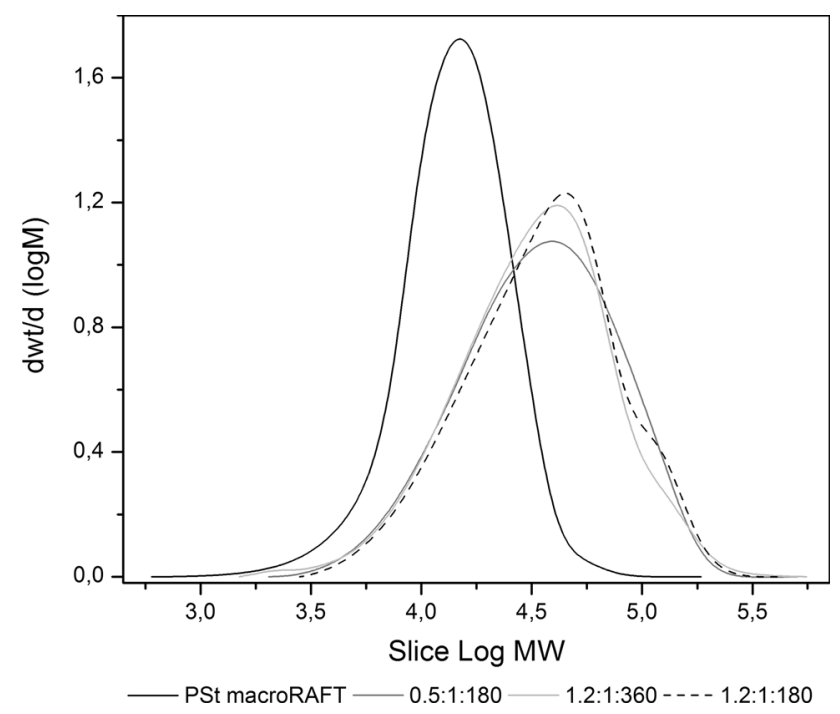

Fig. 1 GPC results of PSt macroRAFT and PSt- $b$-P4VBA synthetized using different ratios

higher chemical shifts can correspond to the vicinity of the phenyl protons of the carboxylic acid group present in P4VBA block. Moreover, the appearance of methylene and methine protons at higher chemical shifts (3.91-4.31 ppm) can also be attributed to the proximity of the sulfur atoms and the carboxylic acid group.

FTIR spectra for PSt macroRAFT and for PSt- $b$-P4VBA are shown in Fig. 3. In FTIR spectrum of PSt- $b$-P4VBA the new broad peak at $3432 \mathrm{~cm}^{-1}$ which corresponds to the $\mathrm{O}-\mathrm{H}$ stretch of the carboxylic acid, confirms the insertion and polymerization of the 4VBA into the PSt macroRAFT. Another new band appears at 1690 and $1283 \mathrm{~cm}^{-1}$, which represents the stretch band $\mathrm{C}=\mathrm{O}$ and $\mathrm{C}-\mathrm{O}$ of the carboxylic acid, respectively. An increased of peak intensity is observed at $1608 \mathrm{~cm}^{-1}$ (aromatic ring) for PSt- $b$-P4VBA when compared with PSt macroRAFT, confirming the polymerization of 4VBA. Two common bands for both compounds are detected at $1105(\mathrm{C}=\mathrm{S})$ and $855(\mathrm{C}-\mathrm{S}) \mathrm{cm}^{-1}$, demonstrating that both synthesized compounds contained a dithiocarbamate end group. 
Fig. 2 a ${ }^{1} \mathrm{H} N M R, b{ }^{13} \mathrm{C} N M R$ spectrum of PSt- $b$-P4VBA prepared by RAFT

polymerization, respectively (a)

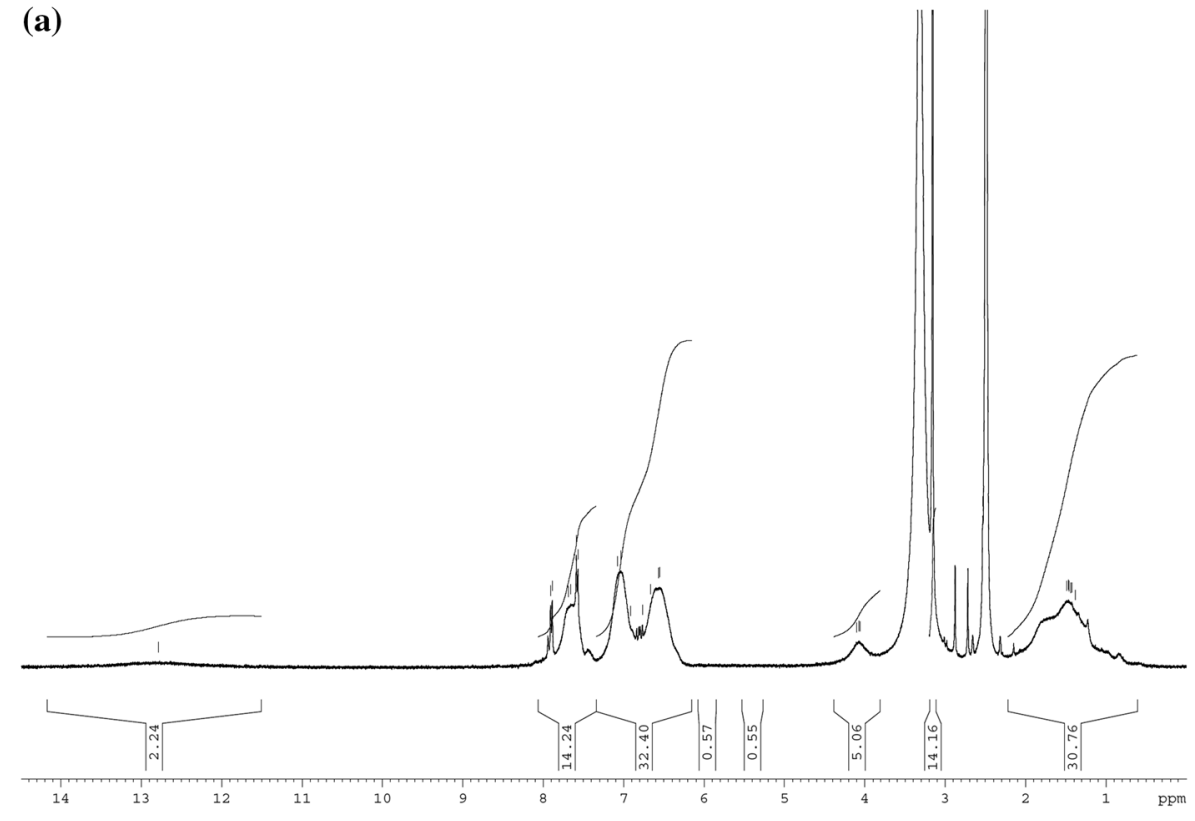

(b)
TGA analyses revealed that poly(4-vinyl benzoic) acid (P4VBA) block has an influence on the thermal stability of polystyrene (Fig. 4). The PSt macroRAFT has lower thermal stability with three degradation stages: first at $100{ }^{\circ} \mathrm{C}$ due to the elimination of solvents and moisture adsorbed, second around $180{ }^{\circ} \mathrm{C}$ expected for dithioate, and the third degradation at $430{ }^{\circ} \mathrm{C}$ for polystyrene segment [23]. The degradation of PSt- $b$-P4VBA occurred in two steps; the lowtemperature weight loss $\left(147^{\circ} \mathrm{C}\right)$ could be due to the dehydration of the carboxylic acid units present in the P4VBA, creating the corresponding anhydride structure [24]. The second weight loss $\left(450^{\circ} \mathrm{C}\right)$ is attributed to the polymer backbones degradation. Generally, copolymers exhibit higher thermal stability than homopolymers, which is also observed in the present study. Likewise, at $500{ }^{\circ} \mathrm{C}$, PSt macroRAFT reaches complete degradation, while PSt$b$-P4VBA presents $10 \%$ of char at $700{ }^{\circ} \mathrm{C}$ (Fig. 4). Such char corresponds to activate porous carbon formation, obtained by dehydration, carbonization, and oxidation of organic substances. Hasegawa and co-workers have been using living radical polymerization techniques to prepare porous carbon form polystyrenes, poly(meth)acrylates, and polyacrylamides copolymers [25].

DSC thermograms of homopolymer and copolymer (Fig. 5) demonstrate that the $T_{\mathrm{g}}$ value for polystyrene segment in the copolymer $\left(100.8{ }^{\circ} \mathrm{C}\right)$ is higher than the $T_{\mathrm{g}}$ 
Fig. 3 FTIR spectra of PSt macroRAFT and PSt- $b$-P4VBA

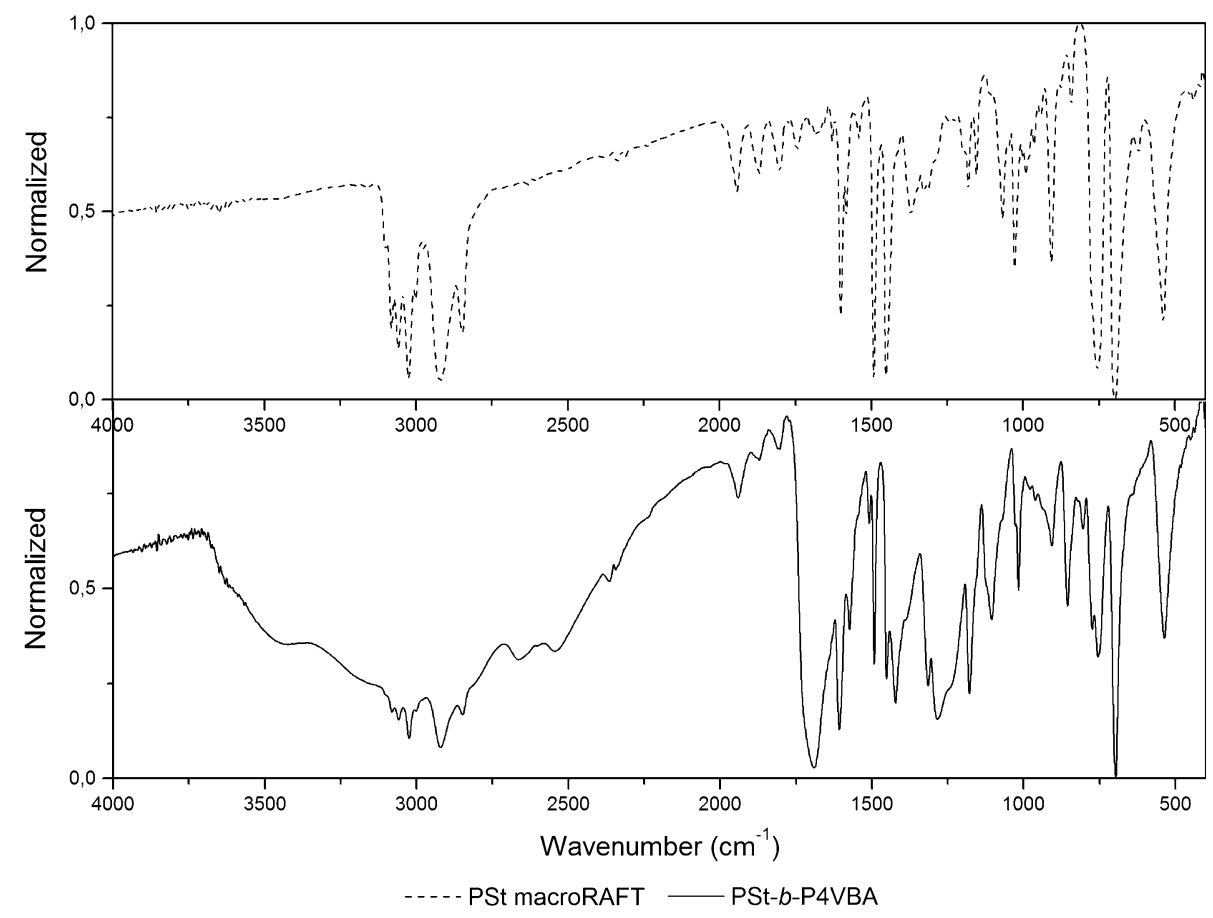

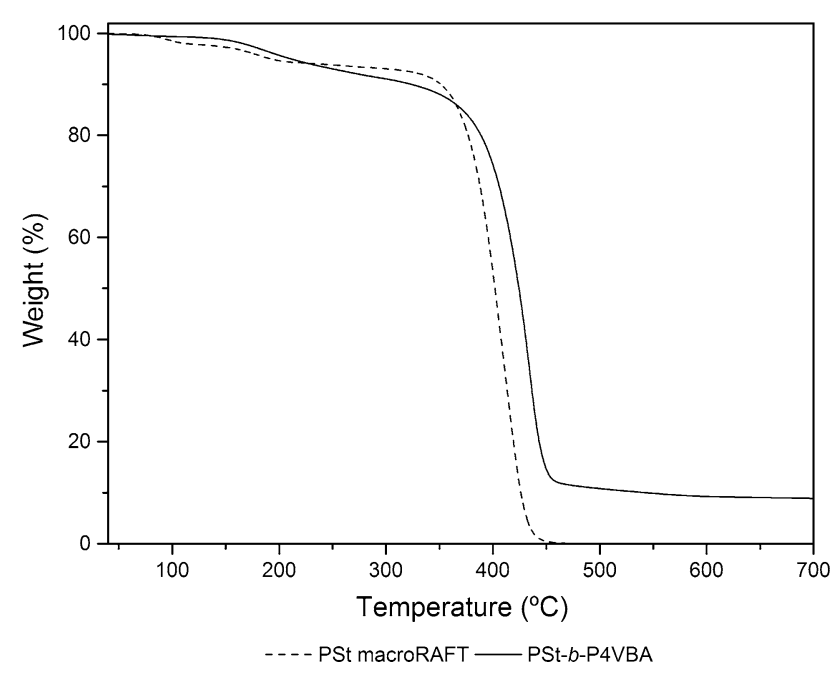

Fig. 4 TGA plots of PSt macroRAFT and PSt- $b$-P4VBA copolymer

value of pristine/homo polystyrene $\left(77.4^{\circ} \mathrm{C}\right)$ owing to the stiffness caused by the polymerization of 4-vinylbenzoic acid into PSt macroRAFT. Furthermore, the PSt macroRAFT glass transition temperature was slight lower than expected. Since the glass transition temperature is molecular weight dependent, a theoretical $T_{\mathrm{g}}$ for PSt macroRAFT can be calculated using the following equation:

$T_{\mathrm{g}}=T_{\mathrm{g}}^{\infty}-\frac{2 \times 10^{5}}{M_{\mathrm{n}}}$,

where $T_{\mathrm{g}}^{\infty}$ the glass transition temperature at infinite molecular weight. The glass transition temperature for PSt

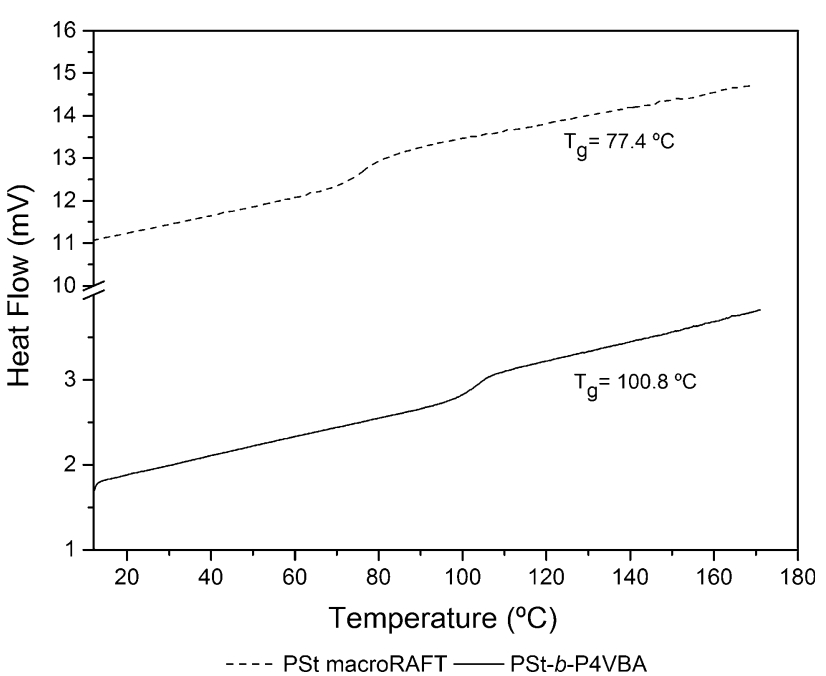

Fig. 5 DSC thermograms of PSt macroRAFT and PSt- $b$-P4VBA copolymer

with a molecular weight of $11852 \mathrm{~g} / \mathrm{mol}$ is approximately $83{ }^{\circ} \mathrm{C}$, which is slightly higher than the one obtained. This indicates that the RAFT endgroup may enhance chain-end mobility, lowering the $T_{\mathrm{g}}$. The same was observed by Beattie and co-workers for PSt- $b$-PAA copolymer [26].

The absence of the individual thermal transition for PSt and P4VBA segments indicates that phase segregation between two domains does not exist demonstrating the copolymer homogeneity.

In order to confirm the absence of crystallinity obtained by DSC, X-ray measurements were carried out for both 
compounds and the results are presented in Fig. 6. X-ray diffractograms exhibited an intense diffraction peaks at $10^{\circ}$ and $19^{\circ}$ for PSt macroRAFT. PSt- $b$-P4VBA shows the same characteristic peaks but with low intensity corroborating the presence of amorphous PSt macroRAFT in the

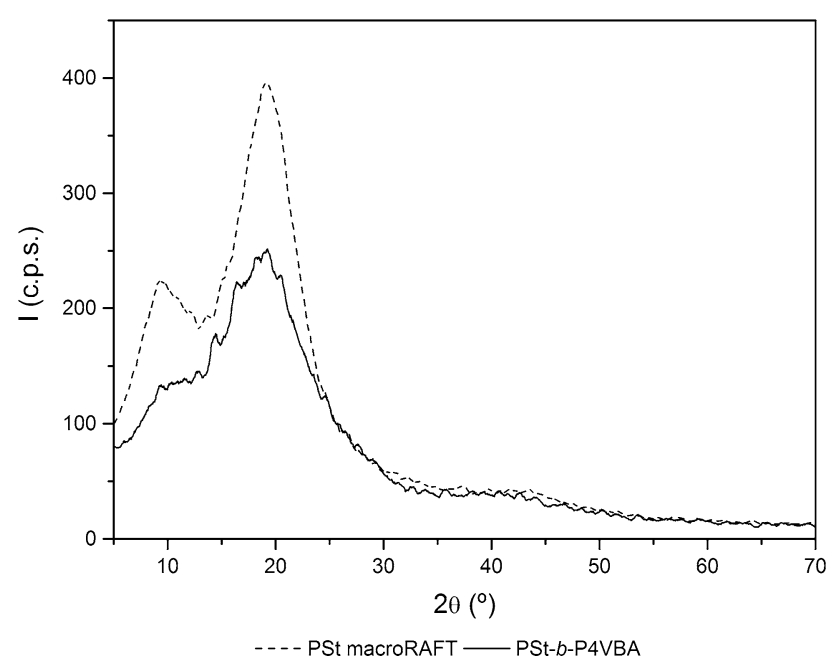

Fig. 6 X-ray difractograms of PSt macroRAFT and PSt- $b$-P4VBA copolymer

Fig. 7 SEM and STEM pictures of $\mathbf{a}$ and $\mathbf{b}$ PSt macroRAFT, $\mathbf{c}$ and $\mathbf{d}$ PSt- $b$ P4VBA copolymer copolymer. Ramesh et al. has observed for PDLLA- $b$ PNVP, achieved similar results, denoting blocks miscibility, which is in agreement with the single glass transition temperature observed by them [27].

Figure 7 shows the SEM and STEM images of the PSt macroRAFT and PSt- $b$-P4VBA copolymer. Surface SEM pictures (Fig. 7a, c) show an increase on surface roughness for PSt- $b$-P4VBA copolymer. Homogenous and continuous structures were obtained for both. PSt macroRAFT STEM pictures depicted the spherical aggregates formation (Fig. 7b), while the 4VBA insertion deformed the PSt spheres creating a diblock copolymer film (Fig. 7d). The synthesized PSt polymer aggregates have a diameter lower than $1 \mu \mathrm{m}$, without size homogeneity. Since particles size is strongly dependent on parameters, such as initiator concentration, monomer, polarity of the reaction medium, polymerization temperature, and the presence of steric stabilizer, the obtained sizes were expected [28]. The alternating light and dark areas observed in Fig. 7d confirm PSt as the main phase and the presence of dark areas (P4VBA) into the light ones.

Mean diameter of PSt macroRAFT and PSt- $b$-P4VBA block copolymer was studied by DLS from a DMF solution. The size of PSt macroRAFT in solution indicated an average of $288.4 \pm 8.3 \mathrm{~nm}$ (PDI $=0.350 \pm 0.098$ ). After

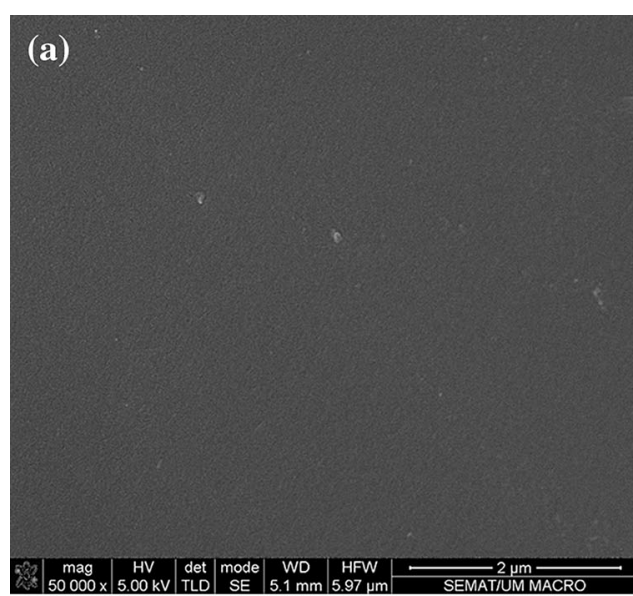

(c)

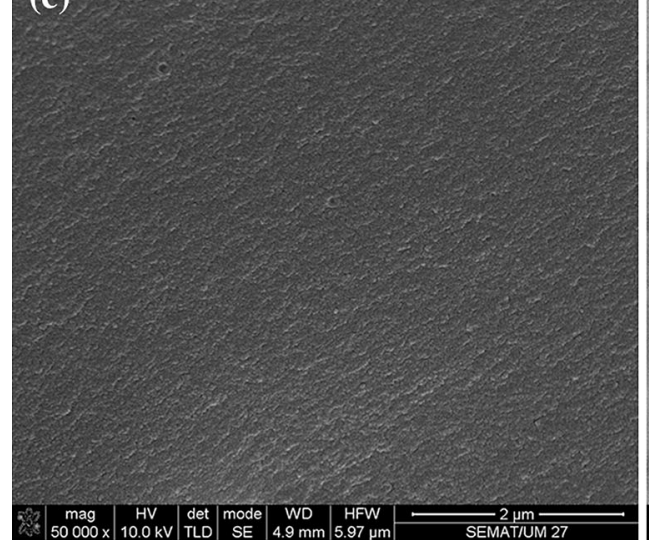

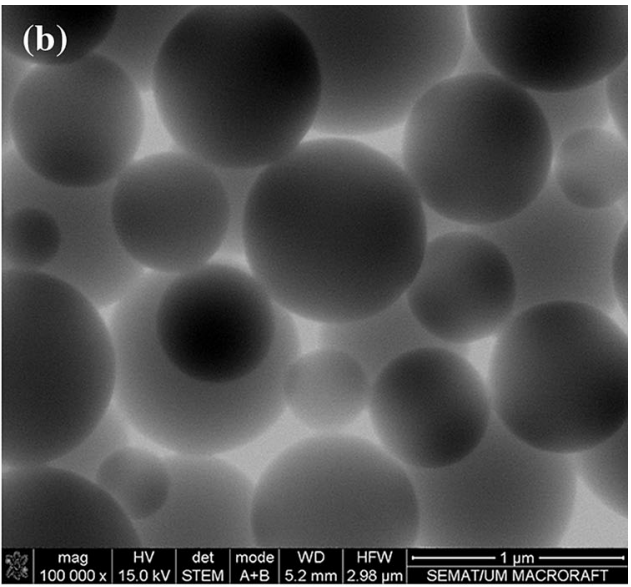

(d)

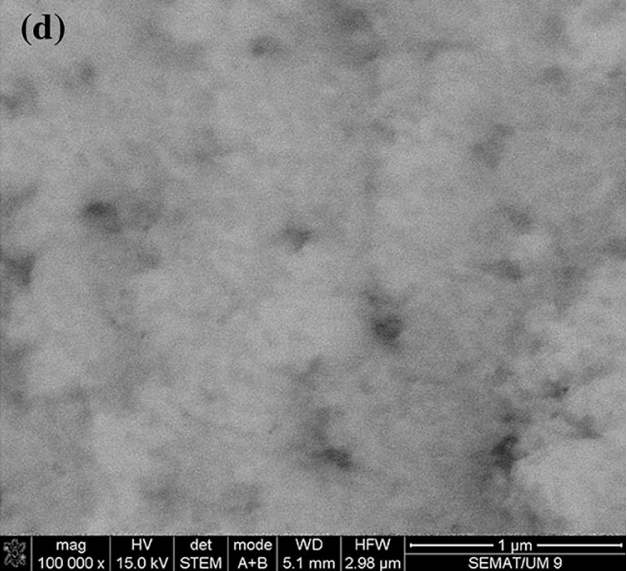


the insertion of the second monomer (4VBA), an increase of the mean diameter for $348.1 \pm 7.4 \mathrm{~nm}(\mathrm{PDI}=0.303 \pm$ 0.109 ) was observed.

\section{Conclusion}

The copolymer PSt- $b$-P4VBA synthetized by RAFT technique was obtained with higher polymerization yield, when reactants molar ratio [PSt macroRAFT]:[AIBN]:[4VBA] was 1.2:1:180. The insertion of 4-vinylbenzoic acid into PSt macroRAFT was performed at $110{ }^{\circ} \mathrm{C}$ in the presence of a RAFT agent benzyl benzodithioate (BDTB) in DMF solution. A morphological evolution was observed with the transition of the homopolymer to the diblock copolymer.

The carboxylic acid functionalized diblock copolymer synthetized is a promising candidate to be coupled to other molecules with available free amino or hydroxyl groups, leading to the development of new materials with innovative properties, such as, fluorescence or photochromic.

Acknowledgements The authors acknowledge the n-STeP-Nanostructured systems for Tailored Performance, with reference NORTE07-0124-FEDER-000039, supported by the Programa Operacional Regional do Norte (ON.2), PEst-C/CTM/LA0025/2013 (Strategic Project-LA 25-2013-2014).

\section{References}

1. Keddie DJ (2014) A guide to the synthesis of block copolymers using reversible-addition fragmentation chain transfer (RAFT) polymerization. Chem Soc Rev 43(2):496-505

2. Hawker CJ, Bosman AW, Harth E (2001) New polymer synthesis by nitroxide mediated living radical polymerizations. Chem Rev 101(12):3661-3688

3. Patten TE, Matyjaszewski K (1998) Atom transfer radical polymerization and the synthesis of polymeric materials. Adv Mater 10(12):901-915

4. Matyjaszewski K (2012) Atom transfer radical polymerization (ATRP): current status and future perspectives. Macromolecules 45(10):4015-4039

5. D'Agosto F (2008) Handbook of RAFT polymerization. Macromol Rapid Commun 29(11):934-935

6. Nilles K, Theato P (2009) RAFT polymerization of activated 4-vinylbenzoates. J Polym Sci Part A 47(6):1696-1705

7. Willcock H, O'Reilly RK (2010) End group removal and modification of RAFT polymers. Polym Chem 1(2):149-157

8. Xu J, He J, Fan D, Wang X, Yang Y (2006) Aminolysis of polymers with thiocarbonylthio termini prepared by RAFT polymerization: the difference between polystyrene and polymethacrylates. Macromolecules 39(25):8616-8624

9. Moad G, Rizzardo E, Thang SH (2011) End-functional polymers, thiocarbonylthio group removal/transformation and reversible addition-fragmentation-chain transfer (RAFT) polymerization. Polym Int 60(1):9-25

10. Moad G, Rizzardo E, Thang SH (2008) Toward living radical polymerization. Acc Chem Res 41(9):1133-1142

11. Hamley IW (2003) Nanostructure fabrication using block copolymers. Nanotechnology 14(10):R39
12. Moad G, Rizzardo E, Thang SH (2013) RAFT polymerization and some of its applications. Chem Asian J 8(8):1634-1644

13. Mitsukami Y, Donovan MS, Lowe AB, McCormick CL (2001) Water-soluble polymers. 81. Direct synthesis of hydrophilic styrenic-based homopolymers and block copolymers in aqueous solution via RAFT. Macromolecules 34(7):2248-2256

14. Lowe AB, Torres M, Wang R (2007) A doubly responsive AB diblock copolymer: RAFT synthesis and aqueous solution properties of poly( $N$-isopropylacrylamide-block-4-vinylbenzoic acid). J Polym Sci Part A 45(24):5864-5871

15. Sumerlin BS, Lowe AB, Thomas DB, Convertine AJ, Donovan MS, McCormick CL (2004) Aqueous solution properties of $\mathrm{pH}-$ responsive $\mathrm{AB}$ diblock acrylamido-styrenic copolymers synthesized via aqueous reversible addition-fragmentation chain transfer. J Polym Sci Part A 42(7):1724-1734

16. Wang R, Lowe AB (2007) RAFT polymerization of styrenicbased phosphonium monomers and a new family of well-defined statistical and block polyampholytes. J Polym Sci Part A 45(12):2468-2483

17. Nilles K, Theato P (2007) Synthesis and polymerization of active ester monomers based on 4-vinylbenzoic acid. Eur Polym J 43(7):2901-2912

18. Aamer KA, Tew GN (2007) RAFT polymerization of a novel activated ester monomer and conversion to a terpyridine-containing homopolymer. J Polym Sci Part A 45(23):5618-5625

19. Zamfir M, Patrickios CS, Montagne F, Abetz C, Abetz V, OssRonen L, Talmon Y (2012) Styrene-vinyl pyridine diblock copolymers: Synthesis by RAFT polymerization and self-assembly in solution and in the bulk. J Polym Sci Part A 50(8):1636-1644

20. Liu B, Kazlauciunas A, Guthrie JT, Perrier S (2005) Influence of reaction parameters on the synthesis of hyperbranched polymers via reversible addition fragmentation chain transfer (RAFT) polymerization. Polymer 46(17):6293-6299

21. Moad G, Rizzardo E, Thang SH (2009) Living Radical Polymerization by the RAFT Process - A Second Update. Aust J Chem 62(11):1402-1472

22. Anderson K, Nazarov W, Musgrave CA, Bazin N, Faith D (2014) Synthesis and characterisation of low density porous polymers by reversible addition-fragmentation chain transfer (RAFT). J Radioanal Nucl Chem 299(2):969-975

23. Yeole N, Hundiwale D, Jana T (2011) Synthesis of core-shell polystyrene nanoparticles by surfactant free emulsion polymerization using macro-RAFT agent. J Colloid Interface Sci 354(2):506-510

24. Nayak PL, Yang K, Dhal PK, Alva S, Kumar J, Tripathy SK (1998) Polyelectrolyte-containing fullerene i: synthesis and characterization of the copolymers of 4-vinylbenzoic acid with C60. Chem Mater 10(8):2058-2066

25. Hasegawa G, Kanamori K, Nakanishi K, Hanada T (2010) Fabrication of activated carbons with well-defined macropores derived from sulfonated poly(divinylbenzene) networks. Carbon 48(6): 1757-1766

26. Beattie D, Wong KH, Williams C, Poole-Warren LA, Davis TP, Barner-Kowollik C, Stenzel MH (2006) Honeycomb-structured porous films from polypyrrole-containing block copolymers prepared via RAFT polymerization as a scaffold for cell growth. Biomacromolecules 7(4):1072-1082

27. Ramesh K, Mishra AK, Patel VK, Vishwakarma NK, Biswas CS, Paira TK, Mandal TK, Maiti P, Misra N, Ray B (2012) Synthesis of well-defined amphiphilic poly(D,L-lactide)- $b$-poly $(N$-vinylpyrrolidone) block copolymers using ROP and xanthate-mediated RAFT polymerization. Polymer 53(25):5743-5753

28. Im SH, Khalil GE, Callis J, Ahn BH, Gouterman M, Xia Y (2005) Synthesis of polystyrene beads loaded with dual luminophors for self-referenced oxygen sensing. Talanta 67(3):492-497 